\title{
Linguistic Human Rights in Tibet: Advocacy and Denial \\ Gerald Roche
}

\section{Introduction: Linguistic Human Rights Advocacy and the Problem of Denial}

In this article, I describe and analyse how my efforts to advocate for linguistic human rights (LHRs) as an engaged scholar have met with resistance in the form of denial from a variety of sources. By denial, I follow scholars such as Cohen (2001) in referring to not only the refusal to acknowledge certain facts, but also to follow through with appropriate interpretations and implications of those facts. This case study of denial and advocacy is important because it demonstrates a significant and unacknowledged challenge that exists in working for linguistic human rights. My discussion builds on and extends prior work on the challenges faced by advocating for linguistic human rights within academia (May, 2005, 2011; Skutnabb-Kangas, 2000; Skutnabb-Kangas \& May, 2016). My exploration of denial aims to open up a space for discussing how this challenge may be addressed, and therefore how to more effective advocate for LHRs.

Focusing on denial enables us to consider advocacy beyond a focus on evidence-based persuasive rhetoric. The existence of denial reveals the significance of non-rhetorical maneuvering that is encountered in undertaking advocacy, and the complex role that evidence plays. Conceptually, my discussion of denial in this regard draws on four bodies of literature: the sociology of denial (e.g., Cohen, 2001; Zerubavel, 2006); the study of denial in human rights advocacy (e.g., Seu, 2013); literature on genocide denial (e.g. Charny, 2003; Behrens, Jensen, \& Terry, 2017; Skutnabb-Kangas 2020); and discussions of 'agenda denial' by political scientists (Cobb \& Ross, 1997).

My discussion focuses on LHRs in Tibet. I begin below with a brief outline of this context, before moving on to describe the advocacy work I have done in relation to the languages of Tibet. I then describe the forms of denial I have encountered in this work, aiming to provide a typology of denials that I expect other advocates might encounter. After this, I look at the motives and strategies that denialists use. In the conclusion I explore how we might deal with the issue of denial in our advocacy for LHRs.

Methodologically, this chapter is inspired by the insights of feminist philosopher Sara Ahmed (2017, 2012), who has describes how we generate knowledge about a situation through our efforts to change it. The practical experience of 'coming up against a world... of trying to transform a world' (2017, p.15) produces knowledge about how that world is maintained. Ahmed (2012) argues that the experience of repeatedly meeting 'walls' in such transformative work is frustrating and debilitating — like banging your head against a wall—but it is also informative. In 
this chapter I use my own experiences advocating for LHRs as a method for producing knowledge about how denial contributes to the refusal to recognize LHRs. My reflections are necessarily personal and post-hoc. I provide further details about sources and presentation of data in the final paragraph of the section 'Advocating for Linguistic Human Rights in Tibet.'

Finally, I also want to provide a note on my positioning as author and producer of knowledge. In this chapter I discuss advocacy for languages I do not speak, on behalf of communities I do not belong to. Here I position myself as a knower: in relation to the LHRs situation in Tibet, but also as an arbiter of what is and isn't denial. It's important to acknowledge that I could be wrong. And, because the privilege that enables me to produce this knowledge is also a form of 'cognitive dysfunction' (Mills 1997), I almost certainly will be wrong in some ways. Furthermore, wherever the knowledge I produce is wrong, then the attached moral and political project of advocacy will also be wrong, in the non-epistemic sense. In making the decision to write about and advocate for LHRs in Tibet, here and elsewhere, I have weighed the existence of these epistemic, moral, and political hazards against the consequences of inaction and silence, and the entailments that are attached to my status as a witness to human rights abuses. My response to this predicament is continued, cautious action, constant reflection, and an openness to the possibility that I may in certain ways that are unknown to me, be in denial.

\section{Linguistic Human Rights in Tibet}

The languages of Tibet and the people who sign and speak them face a myriad of challenges in relations to rights. An important aspect of these challenges is the state's refusal to recognize the existence of most language communities amongst Tibetans. Rather than acknowledging the multilingual reality (Roche, 2014; Roche \& Suzuki, 2018), the state instead represents and treats the Tibetan community as monolingual, possessing only a single Tibetan language with three major dialects (Roche, 2017, 2019). Tibetans have long recognized the diversity of their spoken languages (Roche 2021c), and linguists have identified at least 30 mutually unintelligible spoken varieties among Tibetans in the PRC (Roche and Suzuki 2018), in addition to 'the Tibetan language' and the variety it contains (Tournadre 2014).

This refusal to recognize language communities creates a distinction between Tibetan, as a recognized language that is subordinated to the national language (Putonghua), and the numerous other languages spoken by Tibetans, which are completely erased from all public discourses about language and the policies and practices that derive from them. This distinction between subordinated and erased languages is reproduced across a variety of social institutions, including education, health care, and other government services. 
Beyond this denial of the right to be recognized as distinct language communities, the state also constrains language rights through the administration of even the limited rights that pertain to Tibetan as a recognized, subordinated language. A major issue here is the way in which language rights are administered on a territorial rather than a collective or individual basis. This has a number of important consequences for LHRs. To begin with, an administrative territory (prefecture, province, county), typically only has one or two titular minorities that are recognized, giving us names such as Tibet Autonomous Region, Rnga ba Tibetan and Qiang Autonomous Prefecture, and Rmi li Tibetan Autonomous County. Within these territories only the recognized language of the titular minority is granted rights. So, for example, in the Tibet Autonomous Region, although Monpa and Luoba are recognized as distinct groups with their own languages, they are not granted any rights (for example, to mother tongue education of any form: either as a medium, or as a subject).

Beyond this, two other further problems arise in relation to the territorial administration of rights. First is the fact that individuals that move outside their titular territory essentially forfeit their rights, so that, for example, Tibetans who move to cities outside Tibet are denied mother tongue education no matter how large their population (Yeh \& Makley, 2019). A second issue with the territorial administration of LHRs is these rights are being undermined through 'administrative urbanization,' whereby autonomous territories are converted to metropolitan areas, thus losing their special legal status vis-a-vis minority rights (Bulag, 2002; Roche, Leibold, \& Hillman, 2020).

In addition to the territorial administration of linguistic rights and the refusal to recognize the majority of language communities in Tibet, a third major issue regarding LHRs in Tibet is the aggressive promotion of the PRC's national language, Putonghua. The promulgation of Putonghua is driven by national targets that aim to universalize use of the language amongst the entire citizenry. Less than half the population had some competence in Putonghua as recently as 2006 (China.org.cn 2007). By 2017, this number had been raised to 70 percent, and was set to reach 80 percent by 2020 (BBC News 2017).

This universalization of Putonghua is driven by fundamental legal inequalities: learning and using Putonghua is compulsory, whilst learning and using of recognized minority languages such as Tibetan is optional (Zhou, this volume discusses LHRs in China, and Ayup, Tékin \& Sidick, this volume, discuss LHRs for the Uyghur people of Xinjiang). Learning and using unrecognized languages is meanwhile impossible in all institutional contexts. Putonghua is named and enshrined in the constitution and in a national language law; no other languages are named in national legal mechanisms for language. The vague and optional nature of LHRs for recognized minority languages has seen efforts by the state to expand Putonghua into the few domains where these languages are used, such as mother tongue mediumeducation. Evidence of the 
impacts of this situation can be seen in widespread protests against the promotion of Putonghua, and high rates of endangerment (i.e., coerced language shift) throughout the country.

We can also situate the challenges seen in Tibet within a broader framework of civil and political rights pertaining to language. These issues manifest both domestically within the PRC and in international forums. Domestically, the denial of LHRs is compounded by a variety of political curtailments. For example, there is no democratic, participatory mechanism for the recognition of languages that would enable communities to refute the state's erasure. Even where the state does recognize the existence of a language, attempts to advocate for increased support and domain expansion are suppressed by the state; civil society is heavily, and increasingly, constrained, including the criminalization of language activism in Tibet (Roche, 2021a). A prominent example of this is seen in the case of language rights advocate Tashi Wangchuk, who was arrested and imprisoned for attempting to promote mother tongue medium education (Buckley, 2018). More generally, developments that would support both recognized and unrecognized languages are resisted by reward structures that encourage local government officials and Party members to focus primarily on economic development and social and political stability (Hillman, 2016). They are also stymied by the strong and growing role of human rights 'counter-discourses' in the PRC which "propagate a vision of order in which human rights would have no place, or, at best, a very diminished function..." (Pils, 2018, p.12).

In the international sphere, the PRC works to suppress the LHRs of its citizens through two mechanisms. One is the effort to interfere with the universality of human rights as they are understood and applied in such forums as the UN's Human Rights Council (Worden, 2020). This is based, in part, on the assertion that human rights have been imposed by 'the West' on the international order. A second, similar initiative pursued by the PRC within UN forums is the refusal to acknowledge domestic indigeneity. Although the PRC has supported various statements and mechanisms relating to Indigenous peoples, including the UN Declaration on the Rights of Indigenous Peoples (UNDRIP), this support is due partly to the fact that the PRC sees colonialism as an exclusively European phenomenon. Thus, the strong statements of LHRs found in the UNDRIP, for example, are seen as not pertaining to the PRC because it claims to have no Indigenous people.

What we see, then, is a complex and largely covert set of mechanisms to deny LHRs in Tibet. The foundation of these mechanisms is the denial of the existence of most of Tibet's languages. In refusing to acknowledge this diversity, the PRC also denies Tibetans who speak and sign unrecognized languages the right to "identify with their mother tongue(s) and have this identification accepted and respected by others" (Skutnabb-Kangas, 2000, p. 502). Meanwhile, international critique of the PRC's failures regarding LHRs in Tibet within academia, the media, and among advocates, focuses exclusively on the promotion of Putonghua at the expense of Tibetan. This exclusive focus on Tibetan compounds rather than resisting the PRC's efforts to 
erase unrecognized languages in Tibet, and has failed to provide a meaningful critique of, or any methods of resistance against, the state's eliminationist program targeting these languages.

\section{Advocating for Linguistic Human Rights in Tibet}

Given the situation described above, my intervention in LHRs in Tibet has focused on unrecognized languages, targeting the international sphere rather than the domestic, as I believe that civil society outside of the PRC provides the mostly likely venue for recognition of the existence and plight of unrecognized languages. I have eschewed advocacy within the PRC because my experience living and working there suggested to me that this would be futile, and would likely endanger speakers and signers of unrecognized languages. In this following section I outline some of the advocacy I have undertaken in attempting to raise awareness of the existence of Tibet's unrecognized languages, and the plight of their speakers and signers.

In my academic publications, I have primarily advocated for LHRs by producing, analysing, and presenting new empirical data on the present situation of individual languages in Tibet, and on the existence and specific plight of unrecognized languages in Tibet more generally. I have explored how LHRs are limited by the state, ${ }^{i}$ and have consistently attempted to clearly describe the likely consequences if this situation is not addressed through substantive change.

For example, in an article on LHRs in Tibet, I conclude that a continuation of the current situation "will amount to the continued deprivation of the right to have language rights for the speakers and signers of Tibet's minoritised languages, leading to the ongoing oppression, and likely elimination, of these languages" (Roche, 2021a, p. 77). In another article (Roche 2019: 501) I argue for the importance of recognizing the existence of minoritized languages: "the emergence of genuinely anti-systematic discourses that recognize the existence of these languages is a necessary condition for the institutional change, and redistribution of material and symbolic resources, needed to secure the emancipation of these languages." In other publications (e.g., Roche \& Suzuki, 2018; Roche \& Yudru Tsomu, 2018) I have endeavoured to make similar calls to action explicitly describing the likely consequences of inaction for the speakers and signers of unrecognized languages in Tibet.

In addition to publishing academic articles, I have also spoken publicly about the plight of Tibet's unrecognized languages in a variety of forums. I have given podcast interviews (e.g., Little Red Podcast, 2016; Ear to Asia, 2017), spoken with journalists (New York Times, Wall Street Journal, Globe and Times, CNN, Al Jazeera and Reuters), given public lectures at universities and other venues, presented at conferences and workshops, and published my work in accessible, non-academic formats, including blog posts and op-eds (e.g., Roche, 2020; Roche \& Leibold, 2020; Roche 2018a, 2018b). I have also regularly discussed various aspects of 
Tibetan language politics on social media: on Facebook, through my personal account and through a page I manage (Minoritized Languages of Tibetii); and through my personal Twitter account (@JJosephRoche). In-person presentations and conversations on social media have involved a significant amount of interaction on the topic of unrecognized languages in Tibet.

Most of these activities fit under the rubric of advocacy as 'awareness raising'. They aim to draw attention to a particular situation, disseminate knowledge about it, and suggest actions for people to take. I have also undertaken more targeted, direct advocacy, contacting individuals and organizations and asking them to undertake specific actions. In one example, I emailed a number of organizations that work at the intersection of language and social justice, and asked them to endorse a document providing a 'style guide' for discussing language issues in Tibet in a way that would counter the erasure of unrecognized languages. I have also reached out directly to specific organizations and asked them to publicly acknowledge the existence of Tibet's unrecognized languages, and to consider formulating campaigns that would specifically address the challenges faced by communities that use those languages.

In all of this work I have encountered denial: not simply a refusal to acknowledge facts established with evidence, but also a refusal to follow through with appropriate interpretations of and reactions to those facts. This denial has taken various forms: social media comments, peer review feedback on academic articles, questions and comments at public lectures and conference presentations, conversations and correspondence with representatives of particular organizations, and private conversations with friends, colleagues, and others.

In the following section I attempt to classify the types of denial I have encountered. The experiences I draw on happened, roughly, between mid 2014 and mid 2020. Although many of the denialist statements I analyse are on the public record, I do not present direct quotes or identifying information about interlocutors in this analysis, in order to maintain good faith dialogue and to avoid alienating my interlocutors. My aim here is to explore denial and its impacts, rather than to attribute blame to specific speakers for engaging in denial.

\section{Denial: A Typology}

Denial comes in several forms. I use Stanley Cohen's (2001) threefold division of literal, interpretive, and implicatory denial, and apply it to the situation of LHRs, based on my experience of advocating for Tibet's minoritized languages. In discussion of Cohen's typology, I show how it manifests in relation to the existence of Tibet's minoritized languages, and to the acknowledgement of the oppression they are subjected to. First, I look at Cohen's three types of denial. 
Literal denial is "the assertion that something did not happen or is not true" (Cohen, 2001, p.7). This is denial in the most direct and normative sense of the word, and is what most people think of when they think of denial. However, Cohen argues that we must consider denial beyond this narrow rejection of facts, and thus expands denial to include 'interpretive' and 'implicatory' denial. Interpretive denial involves acknowledgement that something exists, happened, or is taking place, but also includes a refusal to follow through with the appropriate interpretation of this acknowledged fact. Cohen provides the example of someone who recognizes that they drink a lot, but refuses to acknowledge that they are an alcoholic. Finally, implicatory denial involves denying the political and ethical implications of knowing about something. Bruna-Seu (2013) writes about this problem in terms of 'passivity generation': a process that enables people to know about wrongdoings, to be called upon to do something about them, but still remain passive.

In the following discussion of the existence of unrecognized languages and their oppression, I will describe the denial I have encountered according to Cohen's typology.

\section{Denying Diversity: Tibet Doesn't Have Unrecognized Languages}

When advocating LHRs in Tibet, literal denial often involves denying the existence of unrecognized languages. I sometimes encounter this form of denial as confusion or bewilderment: "No, that can't be true!" "Are you sure?" This confusion arises because of the received wisdom that Tibetans are linguistically homogeneous: that all Tibetans speak Tibetan. An interlocutor is engaging in literal denial when they continue reproducing this conventional wisdom despite being presented with evidence to the contrary. This denial sometimes manifests, for example, as an asymmetrical conversation, where I talk about Tibetan languages and my interlocutor talks about Tibetan language.

NGOs, scholars, and journalists that I have spoken to about Tibet's unrecognized languages often continue describing Tibetan language in the singular, and often refuse to mention any of Tibet's unrecognized languages by name. Such blanket refusals to engage are described by Cobb and Ross (1997) as the most low-cost strategy of 'agenda denial'. Zerubavel (2006, p.4) describes such silences as "the most public form of denial."

If literal denial often takes the form of silence, interpretive denial most often takes the form of an explicit argument. When confronted with evidence of the existence of Tibet's minoritized languages, scholars, activists, and others will often acknowledge that diversity exists, but insist that the diversity consists of dialects rather than languages. Such dialectization is a common strategy for refusing linguistic human rights. Kurdish, for example, has been presented as a dialect of Turkish (Skutnabb-Kangas, 2000) and Persian (Hassanpour, 2000). From an LHR perspective, the distinction between language and dialect is important; to deny a variety the 
status of language is to deny it the right to have rights (DeGooyer, Hunt, Maxwell \& Moyn, 2018).

I have repeatedly encountered claims that Tibet's minoritized languages are not languages. At one academic conference I outlined the impacts of failing to recognize the existence of Tibet's minoritized languages. One person replied with a version of the Weinrich witticism, "A language is a dialect with an army and a navy" - a statement I have heard countless times. The deployment of the witticism typically demonstrates the argument made by Maxwell (2018), that this phrase primarily serves to deflate and defer discussions about the political nature of the language-dialect distinction, rather than to acknowledge and promote the need for debate. The witticism thus acts as a rhetorical buffer (Bonilla-Silva, 2002) that aims to reinterpret the language-dialect distinction as arbitrary and hence politically insignificant, rather than as a significant point of contention.

Often, interpretive denial regarding the language-dialect distinction takes much more blunt forms. One discussion at a workshop ended with me and another scholar sitting across a table repeating, 'languages,' 'no dialects' until someone stopped us. In another instance, a senior figure in a Tibetan advocacy group repeatedly referred to 'dialects' when discussing unrecognized languages on social media. When I privately pointed out to them that they were actually describing languages, they replied that they were, "OK knowing there are views on this." Meanwhile, in academic peer review processes, regardless of how much reference to the linguistic literature I provide, and no matter how much testimony I provide from speakers, I am still consistently requested to justify the existence of certain languages as languages. In all these cases, my interlocutors react by attempting to maintain the status quo when presented with evidence that Tibet's unrecognized languages exist.

Efforts to maintain the status quo, and the erasure and elimination it entails for unrecognized languages, is also encountered as implicatory denial. As outlined above, my work has consistently drawn attention to the harmful consequences of the status quo. Nonetheless, there has been little to no follow-through with actions that would change this situation, and when change has taken place, it has been minimal. Two examples of such minimal change will help demonstrate what I mean.

In one case, I met with representatives of a Tibetan advocacy group and gave a presentation on my research into unrecognized languages. I emphasized the importance of recognizing the existence of these languages. The organization did this, by changing the text on their website that described the languages of Tibet and the oppression they face. In another example, a representative of a human rights organization contacted me before giving an important public presentation that involved discussion of LHRs in Tibet. They asked me to clarify a few key 
points about my research. In their public presentation, they acknowledged the existence of minoritized languages.

In both cases, there was no follow-through in terms of research, communication, or campaigning after the public acknowledgement of unrecognized languages. These acknowledgements were important: they broke the silence perpetuated by literal denial, and refuted the dialectization promoted by interpretive denial. However, the failure to follow through with meaningful action - the engagement in implicatory denial — places them within the spectrum of agenda denial described by Cobb and Ross (1997). Within their schema, we can view these actions as a medium-cost strategy of agenda denial, described as showcasing, tokenism, or symbolic placation: appearing to do something without taking substantive action on an issue.

\section{Denying Oppression: Tibet's Unrecognized Languages aren't Oppressed}

My efforts to advocate for LHRs have been hampered by efforts to deny the existence of unrecognized languages, their status as languages, and the ethical and political implications of this status. An additional form of denial I have encountered is denial of oppression: a refusal to acknowledge the political asymmetries, acts of discrimination, and so on, that Tibet's unrecognized languages are subjected to. This denial exists particularly in relation to intra-ethnic aspects of language oppression, i.e., oppression that takes place between Tibetans, promoting a single Tibetan language at the expense of unrecognized languages.

This denial of language oppression involves literal denial. When I have spoken about discrimination against speakers of unrecognized languages, my interlocutors have sometimes simply refused to accept that events I witnessed or collected testimony about ever took place. However, such literal denial has been rare. This is perhaps because, although the literal denial of the existence of unrecognized languages can be defined as a terminological issue, the denial of events and practices involve direct accusations of deliberate falsification, which in my experience many people are unwilling to do.

Interpretive denial has been far more common. This involves refuting the significance of certain events, practices, or structures. For example, my research has focused on the central role that erasure plays in structuring the political predicament of unrecognized languages in Tibet (Roche, 2019). I have also drawn attention to how this erasure is reproduced by institutions of the Tibetan exile government (Central Tibetan Administration), and the NGOs affiliated with it, who thus fail to provide meaningful resistance to the PRC's program of elimination. I made this point a focus of a talk to an audience in Washington DC that included representatives of various NGOs working on the Tibet issue. In responding to this argument, an audience member conceded that the Tibetan exile government and affiliated NGOs do indeed erase minoritized languages. But 
they denied that this had any significance for Tibetans inside Tibet. Erasure was acknowledged as existing, but not acknowledged as a problem.

Another instance of interpretive denial relates to my efforts to raise awareness of various forms of language-based discrimination among Tibetans (Roche, 2021b). Such discrimination is an integral element of the denial of LHRs experienced by Tibetans who speak and sign unrecognized languages. Most of the denial I have encountered in this regard has taken place in personal conversations, rather than public forums. It typically occurs as efforts to minimize and trivialize discrimination (Bonilla-Silva, 2006). "Yes," the conversation goes, "Discrimination occurs. But it isn't really a problem." This is often framed as, "People are just joking - it isn't serious."

Related to minimization and trivialization as forms of interpretive denial, I have also encountered two other forms of denial, described by Charny (2003): definitionalism and rationalization. Definitionalism attempts to deliberately restrict the application of particular terms to all but a very narrow set of entities: "Yes it happened and it is bad but you can't call it X" (where X might be abuse, discrimination, genocide, oppression, etc.). Rationalization, meanwhile, is simply the idea that something bad happened, but the victim deserved it. I have encountered both forms of interpretive denial in advocating for Tibet's unrecognized languages. I have met a refusal to call oppression and discrimination by their names, and also justifications for discrimination against speakers of unrecognized languages (Roche, 2021b).

A final form of interpretive denial that I have encountered is what Cobb and Ross (1997) call 'anti-patterning'. This involves a refusal to see something as part of a broader pattern, and thus originating in institutional discrimination or structural violence. It attempts to turn structural violence into a problem of individual behavior, and consistent patterns of individual behavior into a string of unrelated incidents.

I have not met any implicatory denial regarding the structural violence that Tibet's unrecognized languages are subjected to. But this is perhaps because, as suggested by Keith Kahn-Harris (2018), denialism often occurs in a series, shifting from literal denial (this isn't true), to interpretive denial (this is true but isn't a problem), and then to implicatory denial (this is true and it's a problem but we shouldn't, can't, or won't do anything about it). Most of the claims I have made about the oppression of Tibet's unrecognized languages have either been met with the silence of literal denial, or the deferral of interpretive denial. The concessions to factuality and significance required for implicatory denial have not yet been made.

\section{Denial: Methods and Motives}


We have already encountered several ways in which people 'do' denial (Seu, 2010) in relation to LHRs: silence, dialectization, trivialization, minimization, show-casing, tokenism, and antipatterning. Here, I will expand on this list, and will also discuss the motives of people who engage in denying LHRs, relying on a typology outlined by Israel W. Charny (2003). As we will see, these motives are typically complex, and often benevolent rather than malevolent. As I discuss further in the conclusion, this makes denial harder to deal with.

As discussed above, silence is a common method of denial, and I will briefly expand upon how silence operates as denial. In my case, silence has manifested as unanswered emails, polite avoidance of direct questions, deflections, deferrals, changes of topic, and so on: a repeated refusal to even enter into dialog about Tibet's unrecognized languages. As discussed above, Cobb and Ross (1997) explain that silence is a widespread strategy of denial primarily because it is low-cost. However, silence is also a complex strategy that requires widespread cooperation. Silence is social: it must be normalized and legitimized by its reproduction and circulation, or else it appears in individuals as incivility, asociality, or impoliteness (Zerubavel, 2006). Silence is also cumulative. The normalcy and legitimacy it acquires through circulation deepen over time. The longer it persists the harder it is to break. Silence may thus produce what Sutton and Norgaard (2013) call a 'culture of denial,' where a seemingly passive stance (not talking) actively produces and reproduces something (discursive erasure).

Silence as a method of denial raises important questions about motives. Obviously, someone can not talk about something because they do not know about it, have not been asked about it, and so on. It is therefore difficult to interpret the motive behind silence: is the person or institution engaged in denial, are they simply ignorant, or is something else going on?

In addition to silence, another method of denial that I have encountered is what Seu (2011) calls 'shoot the messenger,' i.e., to attack or discredit the person or organization that is making the claim. Cobb and Ross (1997) refer to this as a 'medium-cost' strategy, and find it to be a common way of retaining control of political agendas once silence fails. In my case, this strategy has primarily been used by Tibetans outside the PRC, who have described my interventions as imperialist, Orientalist, or white supremacist. These claims are based on the very real historical and ongoing exploitation of Tibetans and the Tibetan cause by Westerners. These include not just exploitation of the Tibetan plight to meet geopolitical goals of the USA and other countries (McGranahan, 2010; Halper \& Halper, 2014; Knaus, 2012), but also the racist and Orientalist history of Tibetan studies (Kleisath, 2013; Lopez, 1998). Efforts to describe my advocacy of LHRs as imperialist etc., emerge from this context. These are motivated primarily by a desire to protect and promote a cherished Tibetan identity that is not only under assault from colonialism within the PRC, but also suffers the added insult of global geopolitical exploitation and Orientalist mal-representation. 
In addition to shooting the messenger, these benevolent denials often aim to shift the focus from the specific language I am discussing, or the cateogry of Tibet's unrecognized languages as a whole, to something else. These efforts include, for example, 'advice' that I should focus advocacy on exposing how Putonghua is promoted in the education system. Or, it is suggested that I give equal attention to the fate of Tibetan language in the PRC: that overlooking this issue is a form of cruelty or bias. Although well-intentioned, these efforts attempt to shift focus away from unrecognized languages and towards either Tibetan or Putonghua.

Israel Charny (2003) has discussed how such benevolent denials are widespread in relation to genocide, and are particularly difficult to deal with because, unlike malevolent denials, “...many of the deniers are not committed propagandists or hate-mongers, they are not known to be in the pay or employ of a group ....and in many cases they do not have a record of prejudice and antagonism..." (18). Often such deniers are motivated by an impulse for clarification, the strict policing of terminology, or simply the desire to be seen as good people. Charny also discusses a situation that is relevant to the benevolent denial regarding unrecognized languages and their plight in Tibet: “...denial is at work when people of any one ethnicity, including people and nations who themselves have suffered genocide at the hands of another persecutor and who would be expected to be champions of other victims, declare themselves indifferent to the fates of other people and their claims for historical justice" (25). This describes not only the reaction of many Tibetans, but also their supporters, who are often deeply invested in the Tibetan cause.

The important thing to emphasize in all these cases of benevolent denial is that even though they originate in good intentions, they nonetheless have negative impacts. They unequivocally impede and oppose efforts to raise awareness about Tibet's unrecognized languages and to advocate for LHRs for the people who speak and sign them. They contribute to the maintenance of a harmful status quo.

This is also the case for the final example of denial and its motives that I wish to examine. This is what we might think of as 'banal' denial (in the sense suggested by Arendt, 2007). This is the argument that advocating for Tibet's unrecognized languages is beyond the purview of a particular organization, or that it is within their purview but cannot be aligned with current strategic objectives and campaigning priorities. Cobb and Ross (1997) identify this limiting of institutional authority as a common medium-cost strategy of agenda denial, along with symbolic placation, show-casing, tokenism, and shooting the messenger. As with benevolent denial, banal denial, from the standpoint of the people who use unrecognized languages, has the same impact as malevolent denial: it helps maintain a harmful status quo.

\section{Conclusion}


In the introduction I suggested that the conclusion would address "how we might deal with the issue of denial in our advocacy for LHRs." Here I will discuss this in terms of the two related meanings of 'death with' - in the sense of 'to address' and 'to cope with'. To deal with something might mean to solve a problem, to do away with an issue. Or it might mean to cope with it, to put up with it, but ameliorate its impact. In advocating for LHRs, we need to 'deal with' denial in both senses of the word.

The discussion of denial in this chapter will hopefully help LHR advocates deal with denial, in the sense of cope with it, primarily by naming, describing and analyzing what is a widespread phenomenon, not only restricted to the Tibetan situation (Roche and Troy 2020). When I began my advocacy work, I believed, though was not conscious of the belief, that my main task would be to provide evidence to the relevant authorities, who would then do the right thing. Knowledge would spontaneously translate into action (by other people). Facts would speak for themselves.

I recognize now that this was naïve. Hopefully my discussion of denial will prevent others from similar naivety. Confronting the reality of denial will hopefully provide a shortcut to the sort of disenchantment that prolonged advocacy requires. For me, learning to identify denial and recognize its different forms has helped me cope with the frustrations of encountering it. Learning to expect denial has also diminished the debilitating shock, anger, and anxiety that I first felt when encountering it.

Reading about denial in other contexts has also helped me cope with a sense of personal failure. The literature I have read demonstrates that denial is an inevitable aspect of any effort to transform the world. Denial does not occur because of an insufficiency of evidence, or because of how information is presented, or who presents it. All of these certainly can be issues in advocacy, but advocates should also be aware that claims regarding evidence and advocates can also be used as excuses for denial. As we have seen, people engage in denial for a variety of reasons. And although these reasons can certainly be malevolent, cynical, and self-serving, they are more often benevolent.

Although these insights might help us, as advocates, to deal with denial, in the sense of coping with it, it's also important to consider how we deal with denial in the sense of addressing it. Denial is a problem, regardless of the intentions that underlie it. It always favors the status quo, which is the unjust and harmful situation that advocate aims to change. It also maintains the impunity of those who perpetuate injustice (Opotow, 2001; Melvern, 2020). Denial is thus never harmless or innocent. For advocacy to be effective, denial must be confronted. I therefore want to end with three recommendations about how this can be done.

My first recommendation is based on Keith Kahn-Harris's (2018) distinction between denial on the one hand, and denialism and denialists on the other. He describes denial as a universal 
practice that all people engage in to varying extents. Denialism, meanwhile, is a commitment to deliberate, public and contrarian denial. To be a denialist is to take on denial as an identity. It entails "sheer audacity" and "a degree of commitment that can only be generated by intense determination and desire" (25). Whereas any engagement with denialists tends to entrench them in their position, people engaging in denial can be convinced by more evidence, by new evidence, by different arguments, and by social disapproval.

This connects to a second point, namely that, in the same way that denial is social, so is its opposite: acknowledgement (Cohen, 2001). If individuals engaging in denial can be persuaded, or at least discouraged, then this suggests that over time, a 'culture of acknowledgement' can be created, in the same way that a 'culture of denial' can. This suggests the importance of long-term engagement in combatting denial, in order to build social nodes and networks where acknowledgement flourishes. To address denial in this way, over the long term, it is also essential for advocates to deal with it in the first sense I discussed above: to get used to it, and to cope with it.

Finally, I think it is important to emphasize that inter-disciplinary conversations about denial and denialism are essential. Disciplines such as social psychology have focused on understanding the mechanisms of denial. My discussion here would have been impossible without the insights generated by people such as Irene Bruna Seu, Stanley Cohen, and Eviatar Zerubavel. Meanwhile, work by feminists, environmentalists, genocide historians, and others looks at the difficult but necessary work of finding practical means for resisting denialism. Building effective practices of advocacy for LHRs will necessarily involve learning from and engaging with these disciplines.

\section{References}

Ahmed, S. (2012). On being included: Racism and diversity in institutional life. Duke University Press.

Ahmed, S. (2017). Living a feminist life. Duke University Press.

Arendt, H. (2007). Eichman in Jerusalem: A report on the banality of evil. Penguin.

BBC News. (2017). 'China sets target for $80 \%$ of citizens to speak Mandarin by 2020 ', online at: https:/www.bbc.com/news/world-asia-39484655

Behrens, P., Jensen, O., \& Terry, N. (eds). (2017). Holocaust and genocide denial: A contextual perspective. Routledge.

Bonilla-Silva, E. (2002). The linguistics of color blind racism: How to talk nasty about blacks without sounding "racist". Critical Sociology 28(1-2), 41-64.

Bonilla-Silva, Eduardo. (2006). Racism without racists: Color-blind racism and the persistence of racial inequality in the United States. Rowman \& Littlefield Publishers. 
Buckley, Chris. (2018, 22 May). Tibetan activist Tashi Wangchuk sentenced. New York Times. Retrieved from https://www.nytimes.com/2018/05/22/world/asia/tibetan-activisttashiwangchuk-sentenced.html

Bulag, U. (2002). From Yeke-juu league to Ordos municipality: Settler colonialism and alter/native urbanization in Inner Mongolia. Provincial China 7(2), 196-234.

Charny, I. (2003). A classification of denials of the holocaust and other genocides. Journal of Genocide Research 5(1): 11-34.

China.org.cn. (2007). 'More than half of Chinese can speak Mandarin', online at: http:// www.china.org.cn/english/education/201946.htm

Cobb, R. W., \& Ross, M. H. (1997). Cultural strategies of agenda denial: Avoidance, attack, and redefinition. University of Kansas Press.

Cohen, S. (2001). States of denial: Knowing about atrocities and suffering. Polity Press.

DeGooyer, S., Hunt, A., Maxwell, L., \& Moyn, S. (2018). The right to have rights. Verso Books.

Ear to Asia. (2017). Deciding What's a Language in Tibet (podcast interview). https://player.whooshkaa.com/episode?id=156516

Halper, L. B., \& Halper, S. (2014). Tibet: An unfinished story. C. Hurst.

Hassanpour, A. (2000). The politics of A-political linguistics: Linguists and linguicide. In R. Philipson (ed.), Rights to language: Equity, power, and education. LEA Publishers, 3339.

Hillman, B. (2016). Unrest in Tibet and the limits of regional autonomy. In B. Hillman and G. Tuttle (Eds.), Ethnic conflict and protest in Tibet and Xinjiang. Columbia University Press, 18-39.

Kahn-Harris, K. (2018). Denial: The unspeakable truth. Notting Hill Editions.

Kleisath, M. (2013). Tibet beyond black and white: Racial formations and transnational collusions. PhD Dissertation, University of Washington.

Knaus, J. K. (2012). Beyond Shangri-La: America and Tibet's move into the twenty-first century. Duke University Press.

Little Red Podcast. (2016). The Politics of Language on the Tibetan Plateau (podcast interview). https://omny.fm/shows/the-little-red-podcast/the-politics-of-language-on-the-tibetanplateau

Lopez, D. (1998). Prisoners of Shangri-la: Tibetan Buddhism and the West. University of Chicago Press.

Maxwell, A. (2018). When theory is a joke: The Weinreich witticism in linguistics. Beiträge zur Geschichte der Sprachwissenschaft 28(2), 263-292.

May, S. (2005). Language rights: Moving the debate forward. Journal of Sociolinguistics 9(3), 319-347.

May, S.. 2011 Language rights: The "Cinderella" human right. Journal of Human Rights 10(3), 265-289.

McGranahan, C. (2010). Arrested histories: Tibet, the CIA, and memories of a forgotten war. Duke University Press. 
Melvern, L. (2020). Intent to deceive: Denying the genocide of the Tutsi. Verso Books.

Opotow, S. (2001). Reconciliation in times of impunity: Challenges for social justice. Social Justice Research 14(2), 149-170.

Pils, E. (2018). Human rights in China: A social practice in the shadows of authoritarianism. Polity.

Roche, G. (2014). The vitality of Tibet's minority languages in the twenty-first century. Multiethnica 35, 18-24.

Roche, G. (2017). Introduction: The transformation of Tibet's language ecology in the twentyfirst century. International Journal of the Sociology of Language 245, 1-35.

Roche, G. (2018a). Are debates over linguistic rights erasing diversity? Languages on the Move. https://www.languageonthemove.com/are-debates-over-linguistic-rights-erasingdiversity/.

Roche, G. (2018b). Has the World Lost Site of Tibet? China File. http://www.chinafile.com/conversation/has-world-lost-sight-of-tibet

Roche, G. (2019). Articulating language oppression: Colonialism, coloniality and the erasure of Tibet's minority languages. Patterns of prejudice 53(5), 487-514.

Roche, G. 2020. Beyond Bilingual Education in Tibet. Asia Dialogue https://heasiadialogue.com/2020/03/11/beyond-bilingual-education-in-tibet/

Roche, G. 2021a. Tibetan language rights and civil society in the people's Republic of China: Challenges of and for rights. Asian Studies Review 45(1), 67-82.

Roche, G. 2021b. Lexical necropolitics: The raciolinguistics of language oppression on the Tibetan margins of Chineseness. Language and Communication 76, 111-120.

Roche, G. (2021c). Colonial transformations of song and multilingualism in Tibet. Language Documentation and Conservation, 19, 99-129.

Roche, G. \& Leibold, J. 2020. China's second generation ethnic politics are already here. Made in China Journal. https://madeinchinajournal.com/2020/09/07/chinas-second-generationethnic-policies-are-already-here/

Roche, G., \& Suzuki, H. (2018). Tibet's minority languages: Diversity and endangerment. Modern Asian Studies 54(4), 1227-1278

Roche, G. \& Yudru Tsomu. (2018). Tibet's invisible languages and China's language endangerment crisis: Lessons from the Gochang language of western Sichuan. China Quarterly 233, 186-210.

Roche, G. Troy, J. (2020). Indigenous language denialism in Australia. Languages on the Move. https://www.languageonthemove.com/indigenous-language-denialism-in-australia/

Roche, G., Leibold, J. \& Hillman, B. (2020). Urbanizing Tibet: Differential inclusion and colonial governance in the People's Republic of China. Territory, Politics, Governance https://doi.org/10.1080/21622671.2020.1840427

Seu, I. B. (2010). 'Doing denial': Audience reaction to human rights. Discourse and Society 21 (4), 438-457. 
Seu, I. B. (2011). 'Shoot the messenger': Dynamics of positioning and denial in response to human rights appeals. Journal of Human Rights Practices 3(2), 139-161.

Seu, I. B. (2013). Passivity generation: Human rights and everyday morality. Palgrave Macmillan.

Skutnabb-Kangas, T. (2000). Linguistic genocide in education or worldwide diversity and human rights? LEA Publishers.

Skutnabb-Kangas, T. (2020). Linguistic genocide. In F. Greenland \& F. M. Göçek (Eds.), Cultural violence and the destruction of human communities: New theoretical perspectives. London: Routledge, 58-74.

Skutnabb-Kangas, T., \& May, S.. (2016). Linguistic human rights in education. In T. McCarty \& S. May (Eds.), Language policy and political issues in education: Encyclopaedia of language and education. Springer. Retrieved from 10.1007/978-3-319-02320-5_10-1

Sutton, B., \& Norgaard, K. M. (2013). Cultures of denial: Avoiding knowledge of state violations of human rights in Argentina and the United States. Sociological Forum 28(3), 495-524

Tournadre, N. (2014). The Tibetic languages and their classification. In T. Owen-Smith \& N. W. Hill (Eds.). Trans-Himalayan Linguistics: Historical and Descriptive Linguistics of the Himalayan Area, Berlin and Boston: Walter de Gruyter, 105-129.

Worden, A. (2020). China's win-win at the UN Human Rights Council: Just not for human rights. Sinopsis https://sinopsis.cz/en/worden-win-win/

Yeh, E. T., \& Makley, C. (209). Urbanization, education, and the politics of space on the Tibetan Plateau. Critical Asian Studies 51(1), 1-11.

Zerubavel, E. (2006). The elephant in the room: Silence and denial in everyday life. Oxford University Press.

\footnotetext{
${ }^{i}$ My advocacy has not always been framed explicitly in terms of LHRs. When I began undertaking this work, I employed concepts and framings from endangerment linguistics and Fishmanian sociolinguistics. My first explicit use of a rights framing is found in Roche 2021a. Nonetheless, I think all the scholarship and advocacy I have done is coherent with a linguistic human rights approach.

ii $\underline{\text { https://www.facebook.com/Minoritized-Languages-of-Tibet-1499036023702027 }}$
} 